\title{
Graphene Quantum Dots Doped PEDOT and Its Electrocatalytic Performance for Oxygen Reduction Reaction
}

\author{
Xiangyu Gao ${ }^{l}$, Jinfu $\mathrm{Ma}^{1, *}$, Yingtao $\mathrm{Li}^{2, *}$, Haicheng Wei \\ ${ }^{1}$ School of Material Science and Engineering, North Minzu University, Yinchuan 750021, China \\ ${ }^{2}$ School of Physical Science and Technology, Lanzhou University, Lanzhou 730000, China \\ ${ }^{3}$ School of Electrical and Information Engineering, North Minzu University, Yinchuan 750021, China \\ *E-mail: 1i_yt06@1zu.edu.cn, jinfu_ma@163.com
}

doi: $10.20964 / 2017.12 .63$

Received: 7 September 2017 / Accepted: 21 October 2017 / Published: 12 November 2017

\begin{abstract}
Oxygen reduction reaction (ORR) is key issue for fuel cells because it always produces large polarization thus result in decrease of fuel cell performance. Herein, poly(3,4-ethylenedioxythiophene) (PEDOT) doped with graphene quantum dots (GQDs) was explored as an efficient ORR catalyst. GQDs with size of $3-5 \mathrm{~nm}$ were prepared by thermal reduction at $200^{\circ} \mathrm{C}$. The PEDOT and GQDs@PEDOT were prepared by electropolymerization. Morphology and structure of catalysts were characterized by TEM and Raman. The catalytic activity and stability were investigated by CV, LSV, RDE and CA. Physical characterization indicated that PEDOT had a catenulate structure and GQDs were successfully combined with PEDOT. The results of electrochemical tests showed that the reduction peak current density of ORR was clearly increased after GQDs doping. Calculated by the K$\mathrm{L}$ equation, the number of transferred electrons at $-0.6 \mathrm{~V}$ increased from 2.66 to 3.57, which closed to the theoretical value 4. CA tests indicated that the current density on GQDs@PEDOT electrode was $0.26 \mathrm{~mA} \cdot \mathrm{cm}^{-2}$. The hybrid of GQDs with PEDOT can enhance the catalytic activity and stability for ORR.
\end{abstract}

Keywords: Oxygen reduction reaction; Poly(3,4-ethylenedioxythiophene); Graphene quantum dots; Electrocatalytic activity

\section{$\underline{\text { FULL TEXT }}$}

(C) 2017 The Authors. Published by ESG (www.electrochemsci.org). This article is an open access article distributed under the terms and conditions of the Creative Commons Attribution license (http://creativecommons.org/licenses/by/4.0/). 